Article

\title{
Analysis of the Degradation Process of Alginate-Based Hydrogels in Artificial Urine for Use as a Bioresorbable Material in the Treatment of Urethral Injuries
}

\author{
Jagoda Kurowiak *, Agnieszka Kaczmarek-Pawelska *, Agnieszka G. Mackiewicz ${ }^{\mathbb{D}}$ and \\ Romuald Bedzinski \\ Department of Biomedical Engineering, Institute of Material and Biomedical Engineering, Faculty of Mechanical \\ Engineering, University of Zielona Góra, Licealna 9 Street, 65-417 Zielona Gora, Poland; \\ a.mackiewicz@ibem.uz.zgora.pl (A.G.M.); r.bedzinski@ibem.uz.zgora.pl (R.B.) \\ * Correspondence: j.kurowiak@ibem.uz.zgora.pl (J.K.); a.kaczmarek@ibem.uz.zgora.pl (A.K.-P.); \\ Tel.: +48-683282359 (J.K.); +48-683282576 (A.K.-P.)
}

Received: 31 January 2020; Accepted: 4 March 2020; Published: 6 March 2020

check for updates

\begin{abstract}
Hydrogels from natural polymers such as sodium alginate have great potential in regenerative medicine because of their biocompatibility, biodegradability, mechanical properties, bioresorption ability, and relatively low cost. Sodium alginate, a polysaccharide derived from brown seaweed, is the most widely investigated and used biomaterial in biomedical applications. Alginate dressings are also useful as a delivery platform in order to provide a controlled release of therapeutic substances (e.g., pain-relieving, antibacterial, and anti-inflammatory agents). In our work, we aimed to analyze process of degradation of alginate hydrogels. We also describe an original hybrid crosslinking process by using not one, as usual, but a mixture of two crosslinking agents (calcium chloride and barium chloride). We proved that different crosslinking agents allow producing hydrogels with a spectrum of mechanical properties, similar to the urethra tissue. Hydrogels were formed using a dip-coating technique, and then examined by mechanical testing, FTIR (Fourier-Transform Infrared Spectroscopy), and resorption on artificial urine. Obtained hydrogels have a different degradation rate in artificial urine, and they can be used as a material for healing of urethra injuries, especially urethra strictures, which significantly affect the quality of life of patients.
\end{abstract}

Keywords: sodium alginate; hydrogel material; regenerative medicine; urethra

\section{Introduction}

In tissue regeneration, biodegradable materials are desirable, because they can support tissue healing in the time of need. Biodegradable hydrogels are well known, and they have great potential as biomaterials in regenerative medicine. Currently, hydrogel materials are used on the commercial market as wound dressings, in stomatology, as a coating for catheters, and as drug carriers [1]. Hydrogels made from synthetic polymers more often contain polyethylene glycol (PEG), polyvinyl alcohol (PVA), polyvinylpyrrolidone (PVP), or polyamide [2,3]. Hydrogels made from natural polymers have great potential in regenerative medicine because of their biocompatibility, biodegradability, mechanical properties, bioresorption ability, and relatively low cost. In the group of natural polymers, the most popular and desired hydrogels are gelatin, chitosan, and sodium alginate. They are in use for clinical applications since the 1960s, when they were initially used in ocular applications including contact lenses and intraocular lenses due to their favorable oxygen permeability and lack of irritation leading to inflammation and foreign body reaction, which was observed with other plastics. Hydrogels as 
crosslinked polymeric networks contain hydrophilic groups that promote swelling due to interaction with water. Polymer chain arrangement and the presence of almost $75 \%$ water allows building a structure similar to the extracellular matrix, thereby supporting tissue integration [1,4]. The presence of water in hydrogel and its swelling in the bodily fluids support the diffusion of ions, proteins, and other components that are important for tissue healing. The water which accumulates between the hydrogel polymer chains may also be a carrier for drugs. The swelling and degradation ratio of hydrogel drug carriers influence the drug release close to the target, e.g., skin injury. The polymer chain arrangement and high water content are important in the proliferation phase of wound formation, where epithelization occurs and newly formed granulation tissue consisting of endothelial cells, macrophages, and fibroblasts begins to cover and fill the wound area by producing a new extracellular matrix (ECM). The presence of the new extracellular matrix is crucial for proper healing because it provides conditions for sustaining the cells and blood vessels, which provide nutrients needed to restore the tissue integrity and homeostasis [5]. The extracellular matrix (ECM) also serves as a porous and pliable scaffold for supporting the movement of the cells, nutrients, and growth factors through the wound environment. Studies on the chemical composition of the ECM during wound healing indicated that the deposition of a number of matrix components is different in chronic and acute wounds. The native ECM has the ability to coordinate stromal cells for synthesizing new tissue (e.g., if injured) with control over the tissue structure through the regulation of cell phenotype. Biomaterials act as an artificial ECM and, in the context of a scaffold, they must have biological and mechanical properties that match the native body tissue, and they must facilitate the localization and delivery of cells and/or transforming factors to the desired sites in the body. This includes providing a twoor three-dimensional space for the formation of new tissues with appropriate structure and guiding the development of new tissues with appropriate function [6]. Therefore, drug-incorporated scaffolds with a structure similar to ECM are particularly promising for synergistically accelerating the healing process of chronic wounds [7]. A wide range of applications of hydrogels results from their valuable properties, primarily their ability to swell, which allows water to be accumulated in a particular or desired localization, e.g., in a slow-healing wound. Polymeric hydrogels, due to their specific three-dimensional (3D) structure, are highly biocompatible with soft tissues, and they are able to regenerate the damage tissues and restore their functions. These characteristics make them potential candidates for use in biomedical and pharmaceutical applications such as tissue engineering [8-10]. Chen et al. [11] proved that the 3D microenvironment, especially the elastic and relaxation moduli of the cell culture hydrogel matrix, can regulate the metabolic properties of the living cells. The authors showed that the molecular weight and chemical properties of the polymers used for the cell culture matrix influence the three-dimensional cell culture system. Summa et al. [12] assumed that hydrogel films based on sodium alginate and their polysaccharide chains organized in a 3D structure on a micro level enhance wound healing and induce cell proliferation, whereas the presence of antiseptic povidone iodine in the films prevents bacterial infections.

Sodium alginate, a polysaccharide derived from brown seaweed, is the most widely investigated and used biomaterial in biomedical applications. Alginate is highly hydrophilic and able to absorb wound exudate while maintaining a moist microenvironment. Alginate dressings are also useful as a delivery platform in order to provide controlled release of therapeutic substances (e.g., pain-relieving, antibacterial, and anti-inflammatory agents) [12]. Moreover, their high biological affinity supports tissue integration, and they have biomechanical properties similar to tissues [13-18]. Biomechanical compatibility with tissue is a crucial factor that determines successful tissue regeneration [19]. Researchers, like Barros at al., made attempts to assess hydrogel materials based on sodium alginate, used in ureteral stents, to unblock the ureter and restore the urinary transport function from kidneys to the bladder. The motivation to carry out research on stents for the genitourinary system is the increasing number of male patients with strictures in the urethra, caused by tissue hypertrophy, which impairs the urine flow [20-22]. During the development of novel stents made from hydrogels, particular attention should be paid to the material's mechanical characteristics, especially stress and 
deformation, as well as the stent shape, which should provide a proper interaction in the place of contact between the implant and the tissue [22]. Sodium alginate is a popular and cheap material obtained from brown seaweed. Sodium alginate is anionic and hydrophilic, which enables obtaining a crosslinked polymeric structure with elasticity and strength proper for tissue regeneration. Sodium alginate contains residues of the $\alpha$-L-guluronic acid (G-blocks) and $\beta$-D-mannuronic acids (M-blocks). The G-blocks have a snake structure, while M-blocks have of a more stretched structure than G-blocks. G-blocks and M-blocks are connected by glycosidic bonds. The guluronic and mannuronic acid residues in the hydrogel structure may arrange in three variants/configurations: two $\beta$-D-mannuronic acids residues (MM), two $\alpha$-L-guluronic acid residues (GG), or alternating connections of the $\mathrm{M}$ - and G-blocks (MG). The hydrogels obtained from alginate with a higher number of $\beta$-D-mannuronic acid residues have higher elasticity than those made from alginate with a higher number of $\alpha$-L-guluronic acid residues $[13,14,16,17,23]$. One of the mechanisms leading to the formation of alginate hydrogels is crosslinking by divalent cations, like $\mathrm{Ca}^{2+}$. The G-blocks in the alginate bond with cation in the polymer chains, forming a structure called an "egg-box". The divalent cation bonds covalently with two polymer chains and four G-blocks (two from each chain). The number of divalent ions and their dimensions determine the physicochemical properties of the hydrogel. The affinity of alginates for divalent ions decreases in the following order: $\mathrm{Pb}>\mathrm{Cu}>\mathrm{Cd}>\mathrm{Ba}>\mathrm{Sr}>\mathrm{Ca}>\mathrm{Co}, \mathrm{Ni}, \mathrm{Zn}>\mathrm{Mn}$ [24]. A hydrogel structure crosslinked by divalent ions may be spread by single-valent ions like sodium or potassium, which exchange the divalent ions in the "egg-box" structure, leading to a decrease in the attraction force between G-blocks, thereby increasing the distance between them until they become free from the polymeric structure.

The research described in the present work is focused on the alginate crosslinking process and the resorption on artificial urine, which is rich in sodium and potassium. Motivation for the research and analysis was based on actual problems with tissue regeneration in the urinary tract, especially the urethra. In our research, we developed a hydrogel material able to prevent and to heal urethra strictures, caused by wound healing after surgical treatment, inflections, and other reasons. Alginates are natural polymers, which can build hydrogels with properties similar to soft tissues. In this paper, we aimed to analyze the process of alginate hydrogel crosslinking and the degradation of the alginate hydrogels in artificial urine. We also describe an original hybrid crosslinking process using not one, as usual, but a mixture of two crosslinking agents (calcium chloride and barium chloride). It is assumed that different cross-linking agents allow producing hydrogels with different degradation rates in artificial urine, with a spectrum of mechanical properties, similar to the urethra tissue. The aim was to obtain an alginate-based hydrogel that can be used as a biodegradable material for the healing of urethra injuries, especially urethra strictures, which significantly affect the quality of life of patients. In this work, we analyze two processes: crosslinking and degradation of alginate hydrogels.

\section{Materials and Methods}

\subsection{Materials}

All chemical components used in the research were as follows: alginic acid sodium salt (Sigma-Aldrich, 180947) with the parameters viscosity $15-25 \mathrm{cP}, 1 \% \mathrm{H}_{2} \mathrm{O}, \mathrm{pH}$ 6.5-8.5, molecular weight $120-190 \mathrm{~g} / \mathrm{mol}$, and density $1.601 \mathrm{~g} / \mathrm{cm}^{3}$; calcium chloride (Sigma-Aldrich), barium chloride (Sigma-Aldrich), urea (Sigma-Aldrich), sodium chloride (Sigma-Aldrich), ammonium chloride (Chempur), sodium sulfate (Avantor Performance Materials Poland S.A.), and monobasic sodium phosphate (Avantor Performance Materials Poland S.A.). All solutions were prepared using deionized water. The artificial urine solution was prepared according to the recipe described by Mayrovitz and Sims [25], which is presented in Table 1. 
Table 1. Components of artificial urine with the amount needed to prepare $1 \mathrm{~L}$ of solution.

\begin{tabular}{ccc}
\hline Source & Chemical Reagent & Quantity in Grams \\
\hline Sigma-Aldrich & Urea & 124.9 \\
Sigma-Aldrich & $\mathrm{NaCl}$ & 45.0 \\
CHEMPUR & $\mathrm{NH}_{4} \mathrm{Cl}$ & 12.85 \\
Avantor Performance Materials Poland S.A. & $\mathrm{Na}_{2} \mathrm{SO}_{4}$ & 15.0 \\
Avantor Performance Materials Poland S.A. & $\mathrm{NaH}_{2} \mathrm{PO}_{4}$ & 13.7 \\
\hline
\end{tabular}

The sample preparation, as well as the determination of the degradation process, mechanical properties, and FTIR (Fourier-Transform Infrared Spectroscopy) research methodology, is described below. The nomenclature of the samples and the examined concentrations of sodium alginate and crosslinking agents are presented in Table 2 . The amounts of alginate and crosslinking agents were selected on the basis of the results of other researchers [21,26].

Table 2. Type and name of prepared materials based on sodium alginate.

\begin{tabular}{|c|c|c|c|}
\hline Type of Crosslinker & $\begin{array}{l}\text { Concentration of } \\
\text { Crosslinker }\end{array}$ & $\begin{array}{c}30 \mathrm{mg} / \mathrm{mL} \\
\text { Sodium Alginate }\end{array}$ & $\begin{array}{c}50 \mathrm{mg} / \mathrm{mL} \text { Sodium } \\
\text { Alginate }\end{array}$ \\
\hline $\begin{array}{c}\mathrm{CaCl}_{2} \\
\mathrm{CaCl}_{2} / \mathrm{BaCl}_{2}\end{array}$ & $1.0 \mathrm{M}$ & $\begin{array}{c}\text { 3.0Ca1.0 } \\
\text { 3.0CaBa1.0 }\end{array}$ & $\begin{array}{c}\text { 5.0Ca1.0 } \\
\text { 5.0CaBa1.0 }\end{array}$ \\
\hline
\end{tabular}

\subsection{Samples Preparation}

To prepare samples with different amounts of sodium alginate and different crosslinking levels, $30 \mathrm{mg} / \mathrm{mL}$ and $50 \mathrm{mg} / \mathrm{mL}$ sodium alginate was dissolved in deionized water. The solutions were mixed for $16 \mathrm{~h}$ at room temperature using an electromagnetic stirrer. After stirring, the alginate solutions were sonicated using a sonic washer to remove the air bubbles. Formation of alginate hydrogel samples was carried out by crosslinking of the sodium alginate solution using three different crosslinking solutions with $1 \mathrm{M}$ concentration: calcium chloride, barium chloride, and a mixture of calcium and barium chloride (volume ratio 1:1). The samples were formed as beads with dimensions of $10 \mathrm{~mm}$ and $2 \mathrm{~mm}$ thickness (for resorption and FTIR) and as tubes of 5-6 mm width, 6-7 mm free outer radius, and $0.55-0.63 \mathrm{~mm}$ thickness for mechanical testing (Figure 1a). The mechanical examination of the tubular hydrogel samples using a static tensile test is related to the proposed application of the obtained hydrogel as a biodegradable material for tubular stents for healing of the urethra injuries, which have a tubular shape. The alginate beads were formed in a 3D-printed mold, and the alginate tubes were formed using the dip-coating method on a polymer matrix (Figure 1b). The material was manufactured at an ambient temperature of $23^{\circ} \mathrm{C}$. 


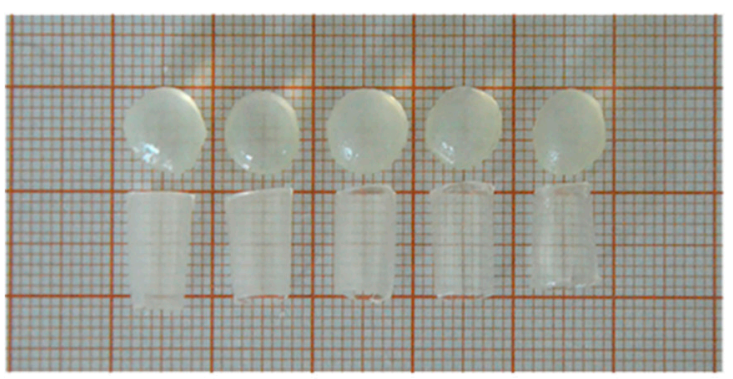

(a)

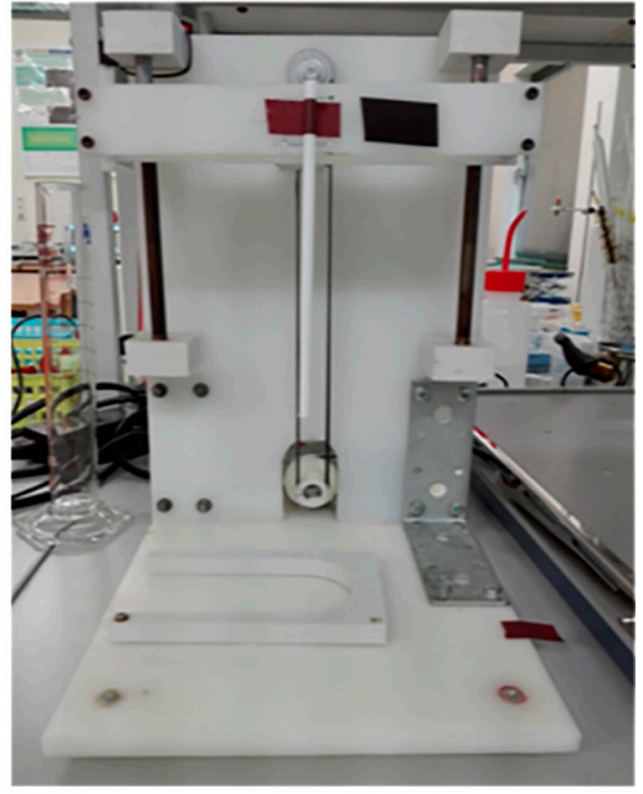

(b)

Figure 1. (a) Samples of hydrogel material; (b) station for forming hydrogel material in the shape of tubes.

\subsection{Degradation, Swelling, and Water Loss}

Material degradation studies were performed in an artificial urine solution prepared according to the recipe AU-5 of Mayrovitz and Sims [25]. The resorption was performed for all materials, repeating the procedure three times for each type of sample with specified concentrations of sodium alginate and crosslinker. The resorption studies were carried out for 14 days via continuous immersion of samples in artificial urine. Each sample was immersed in sterile containers with $15 \mathrm{~mL}$ of artificial urine. The temperature of the artificial urine solution and test conditions was $23^{\circ} \mathrm{C}$. After the set time of immersion in urine, the hydrogel was drained off with a laboratory filter for $15 \mathrm{~s}$. The material resorption or swelling was calculated based on Equation (1).

$$
\text { Resorption or swelling }(\%)=\left[\left(\mathrm{M}_{0}-\mathrm{M}_{1}\right) / \mathrm{M}_{0}\right] \times 100 \text {, }
$$

where $\mathrm{M}_{0}$ is the initial mass of the sample before immersion in the artificial urine solution, and $\mathrm{M}_{1}$ is the wet mass of the sample after immersion in the artificial urine solution.

The loss of water from the tested samples was determined on the basis of an analysis of change in the sample weight after drying for $2.5 \mathrm{~h}$ in a dryer while maintaining a constant temperature of $70{ }^{\circ} \mathrm{C}$. The loss of water was calculated based on Equation (2).

$$
\text { Water loss }(\%)=\left[\left(\mathrm{M}_{1}-\mathrm{M}_{\mathrm{s}}\right) / \mathrm{M}_{1}\right] \times 100 \text {, }
$$

where $\mathrm{M}_{1}$ is the wet mass of the sample after immersion in the artificial urine solution, and $\mathrm{M}_{\mathrm{s}}$ is the sample mass after drying in an oven at $70{ }^{\circ} \mathrm{C}$ for $2.5 \mathrm{~h}$.

\subsection{Examination of Mechanical Properties}

Mechanical testing of the obtained tubular samples (Figure 2) was carried out using a testing machine with an electromechanical actuator Zwick Roel EPZ 005. The alginate hydrogel tubes were examined in a static tensile test in the radial direction with a speed of $5 \mathrm{~mm} / \mathrm{min}$, according to Reference [27]. To measure the geometrical parameters of the samples, especially the surface area, 
the samples were photographed. The photos were analyzed and the surface area was calculated using MS Office 2016. The Young's modulus value was calculated for the linear region of deformation at $0.05 \mathrm{~mm} / \mathrm{mm}$. The tests were conducted at a temperature of $23^{\circ} \mathrm{C}$.

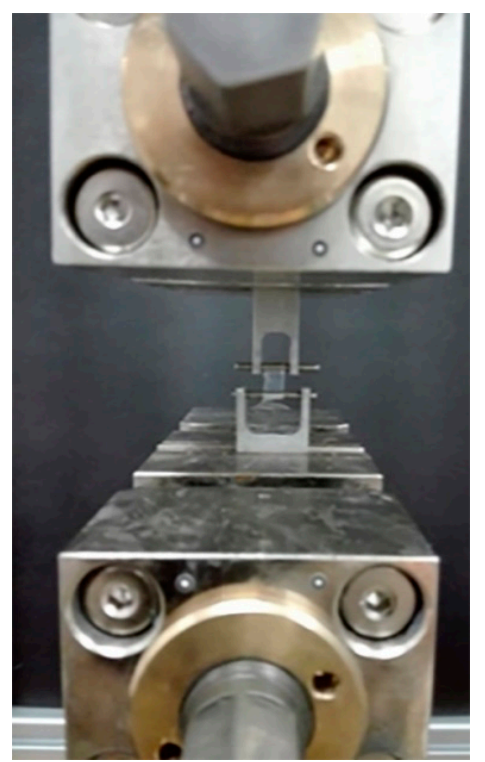

Figure 2. Tensile test tubular hydrogel material on the machine.

\subsection{Fourier-Transform Infrared Spectroscopy (FTIR)}

To determine the composition of the alginate samples and the crosslinking agent bondage, the samples were examined using FTIR-ATR (Fourier-Transform Infrared Spectroscopy-Attenuated Total Reflection). The tests were carried out on a Thermo Scientific ${ }^{\mathrm{TM}}$ Nicolet $^{\mathrm{TM}}$ iS50 FTIR Spectrometer. The absorption was measured within the range of 500 to $4000 \mathrm{~cm}^{-1}$ using an ATR detector with a resolution of 16 scans per spectrum. Before testing, the samples were dried for $12 \mathrm{~h}$ to get rid of the water, which could distort the spectrum.

\section{Results and Discussion}

\subsection{Degradation, Swelling, and Water Loss}

Resorption of the ball-shaped sodium alginate material was carried out for samples with different concentration combinations of sodium alginate and crosslinker. The results obtained for the pre-drained material are presented graphically in Figure 3. Their analysis shows that the type of crosslinking substance affected the resorption time of the material. It was observed that samples with both $30 \mathrm{mg} / \mathrm{mL}$ and $50 \mathrm{mg} / \mathrm{mL}$ sodium alginate dissolved in $100 \mathrm{~mL}$ of deionized water crosslinked with different combinations of crosslinkers showed different degrees and times of degradation. Samples of the materials crosslinked with $\mathrm{Ca}^{2+}$ cations featured slow material degradation, causing point-blank swelling in extreme cases by up to $50 \%$. This was most likely due to the penetration and replacement of free bonds and cation sites by $\mathrm{H}_{2} \mathrm{O}$ molecules into the deeper layers of the material, which were exposed after partial degradation in the initial period of immersion in artificial urine. In case of the 5.0Ca1.0 sample during the 14-day test of resorption, the sample mass grew, showing large swelling, while the 3.0Ca1.0 sample did not begin to degrade until 12 days. The hydrogel material crosslinked with the $\mathrm{Ca}^{2+} / \mathrm{Ba}^{2+}$ cation combination showed degradation throughout the entire 14-day resorption study cycle. Both 5.0 CaBa1.0 and 3.0CaBa1.0 samples lost weight. After completion of the degradation studies (14 days), their mass decreased by an average of about $18 \%$. Assuming that the conducted biodegradation tests were accelerated tests, because the sample was immersed continuously in the artificial urine, it can be assumed that the material would be able to stay in the urethra for up to 77 days 
(11-12 weeks). The water loss in the material after drying at $70{ }^{\circ} \mathrm{C}$ for $2.5 \mathrm{~h}$ for all samples was about $75 \%$ on average.

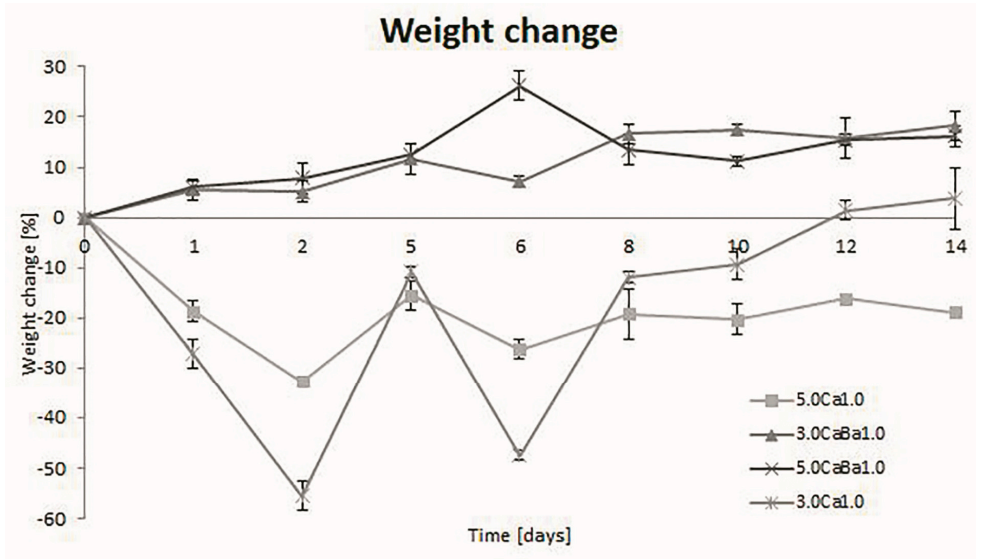

Figure 3. Assessment of wet mass change of hydrogel materials based on sodium alginate crosslinked with $\mathrm{Ca}^{2+}$ cations and $\mathrm{Ca}^{2+} / \mathrm{Ba}^{2+}$ mixture during continuous immersion in an artificial urine solution after pre-draining in a laboratory filter for $15 \mathrm{~s}$.

The obtained results are comparable to those described in the literature [21,28], where it was also observed that the time and rate of the resorption are affected by the ratio of the concentrations of the polymer used and the crosslinker. An important aspect when analyzing the degradation of the hydrogel materials dedicated to future application as stents of the genitourinary system is the amount of urine excreted throughout the day. According to the research carried out by Barros, it appears that their proposed material is intact for up to three days, while, after 10 days, there is full degradation [21].

\subsection{Mechanical Properties of Alginate Hydrogels}

Mechanical examinations of the tubular hydrogel samples were carried to determine the strain characteristics and elasticity in terms of the Young's modulus value. The average values of Young's modulus following six repetitions for each type of material are presented in Figure 4. The results show that using the mixture of calcium and barium ions as a crosslinking agent led to the formation of hydrogels with a higher value of longitudinal elasticity in comparison to crosslinking with only calcium ions. Moreover, the Young's modulus value was the highest for samples with $50 \mathrm{mg} / \mathrm{mL}$ sodium alginate. The obtained mechanical properties of the alginate hydrogels were similar to those of the urethra, and the potential of using the proposed hydrogels for urethra injury healing is promising. The urethra mechanical properties described in the literature are different. Yao et al. [29] provided evidence of human urethra strength with a Young's modulus of 2.4 MPa. More researchers described the White New Zealand Rabbit urethra properties. Zhang et al. [30] published that the Young's modulus for this tissue is $0.25 \mathrm{MPa}$, and Feng et al. [31] stated that it is $0.5 \mathrm{MPa}$. The differences in this value for animal models may be caused by features of individual variation. The tissue properties of animal and human models depend on the age of the model, as well as its health and living conditions. The human urethra strength may also depend on these factors. Mechanical properties of alginate hydrogels were also described by researchers; however, as they used other sodium alginate concentrations and calcium ions as a crosslinking agent, a comparison of obtained results is difficult. In the literature, there are no results related to a mixture of crosslinking ions. A comparison of the obtained results in terms of the mechanical strength for different sodium alginate hydrogels and crosslinking agents described in the literature is presented in Figure 4.

The mechanical characteristics of the urethra show the features of a hyper-elastic material. In order for a stent structure to be used as an implant to unblock fibrosis in the urethra during flow, the stiffness of the material should be close to or higher than the stiffness of the tissue into which it will be inserted. It is best for a hydrogel stent to work in a resilient deformation range. The study showed that, 
depending on the hydrogel concentration applied and the type of crosslinking agent, values close to or higher than the Young's modulus of a rabbit urethra could be obtained. Further evaluation of the results obtained could be achieved by conducting clinical trials using the proposed materials in the form of a urethra stent.

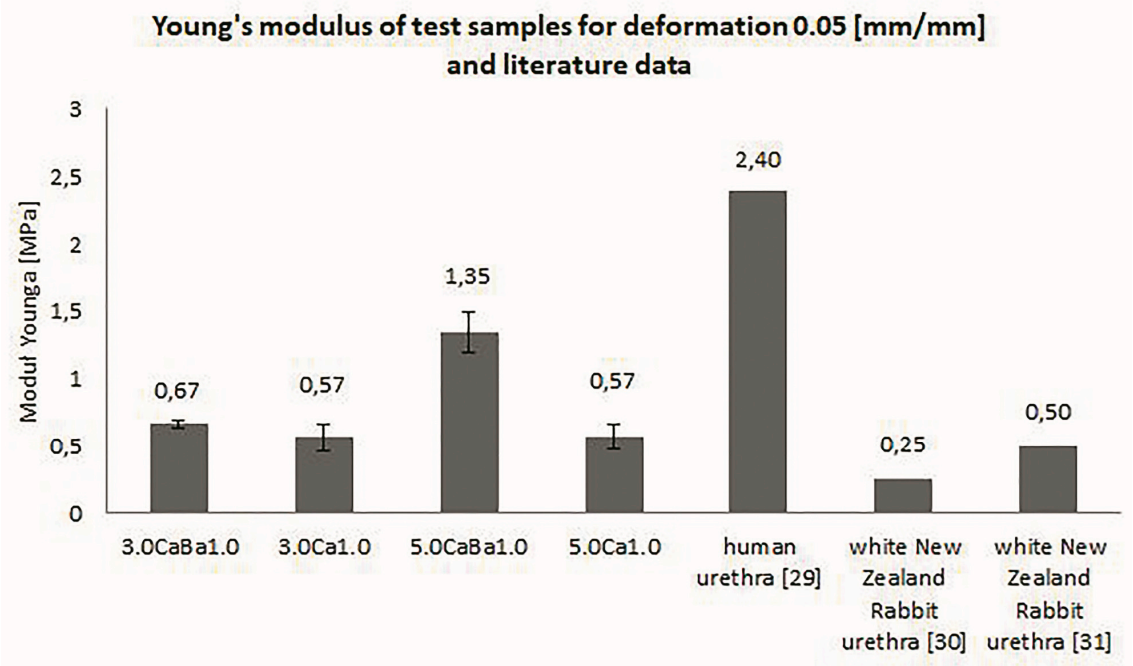

Figure 4. Young's modulus values for tubular alginate samples obtained in mechanical testing.

\subsection{Fourier Transform Infrared Spectroscopy (FTIR-ATR)}

The FTIR-ATR spectra for the alginate hydrogel samples crosslinked with calcium and a mixture of calcium and barium ions are presented in Figure 5. The analysis revealed differences in the absorbance values for the examined sodium alginate concentrations and crosslinking agents. The absorbance in the range 3000 to $3500 \mathrm{~cm}^{-1}$, characteristic for the stretching of hydroxyl bonds $(\mathrm{O}-\mathrm{H})$, was the highest for samples crosslinked with calcium ions. Tensile vibration bands of symmetrical and asymmetrical CO carboxyl bonds and divalent ions were observed at values ranging from 1400 to $1600 \mathrm{~cm}^{-1}$, while bands from 1000 to $1200 \mathrm{~cm}^{-1}$ characteristic for $\mathrm{C}-\mathrm{O}$ bond vibration, at $800 \mathrm{~cm}^{-1}$ characteristic for mannuronic acid, and at $700 \mathrm{~cm}^{-1}$ characteristic for guluronic acid were also observed upon binding crosslinking ions $[32,33]$.

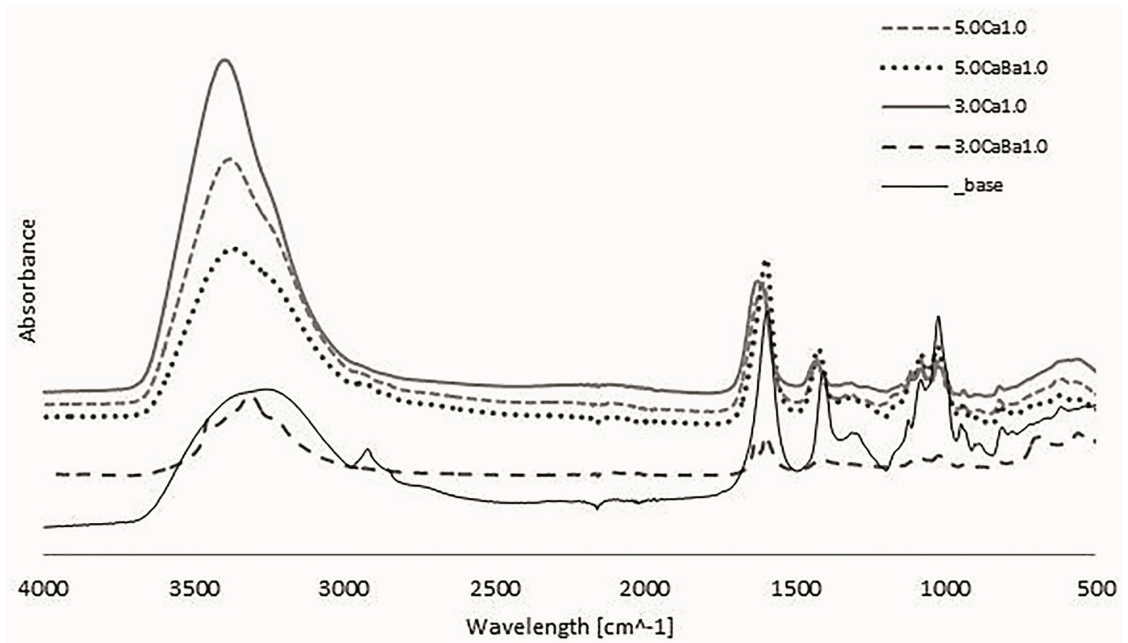

Figure 5. FTIR (Fourier Transform Infrared Spectroscopy) spectrum analysis for alginate samples. 


\section{Conclusions}

Hydrogel materials, in particular those based on natural polymers, have great potential, and they gave promising results in tissue engineering research. Their properties including their 3D structure, high water content, and many others support tissue regeneration. The hydrogels based on natural polymers, especially on sodium alginate, allow increasing the effectivity and development of novel products and knowledge in tissue engineering and regeneration medicine [20,21]. The alginate-based hydrogels developed in the presented research show their potential as a material for genitourinary tissue healing. The obtained alginate hydrogels have mechanical properties similar to the urethra tissue, and they contain $75 \%$ water, which is also a value compatible with the water content in tissues. The content of alginate and crosslinking with a mixture of divalent calcium and barium ions increased the tensile strength with an influence on the resorption ratio and swelling process. The results show that further research can be carried out, aimed at even more accurate analysis, leading to the improvement of the material properties of ureteral stents based on sodium alginate. By choosing the right ratio of ingredients, it is possible to obtain a material with the desired physicochemical properties and adjust the resorption process ratio. Hydrogels are materials that can be easily formed in various shapes depending on the needs and place of application in the body. When developing the degradation and strength properties of urethra stents in the future, it is absolutely necessary to take into account the actions of muscles, urine flow simulations, and the technology of introducing the stent.

Author Contributions: Conceptualization, J.K., A.K.-P., and R.B.; methodology, J.K., A.K.-P., A.G.M., and R.B.; software, J.K. and A.G.M.; validation, J.K., A.K.-P., and R.B.; formal analysis, A.K.-P. and R.B.; investigation, J.K., A.K.-P., and A.G.M.; resources, J.K., A.K.-P., A.G.M., and R.B.; data curation, J.K.; writing-original draft preparation, J.K.; writing-review and editing, A.K.-P. and R.B.; visualization, J.K.; supervision, A.K.-P. and R.B.; project administration, A.K.-P. and R.B.; funding acquisition, R.B. All authors have read and agreed to the published version of the manuscript.

Funding: This research was funded by the National Science Center Poland, grant number DEC-2016/21/B/ST8/01972.

Conflicts of Interest: The authors declare no conflicts of interest.

\section{References}

1. Saul, J.M.; Williams, D.F. 12-Hydrogels in Regenerative Medicine. In Handbook of Polymer Applications in Medicine and Medical Devices, 2nd ed.; Modjarrad, K., Ebnesajjad, S., Eds.; Elsevier Inc. William Andrew: San Diego, CA, USA, 2013; pp. 279-302.

2. Aljohani, W.J.; Wenchao, L.; Ullah, M.W.; Zhang, X.; Yang, G. Application of Sodium Alginate Hydrogel. J. Biotech. Biochem. 2017, 3, 19-31. [CrossRef]

3. Lee, K.Y.; Mooney, D.J. Alginate: Properties and biomedical applications. Prog. Polym. Sci. 2012, 37, $106-126$. [CrossRef]

4. Budama-Kilinc, Y.; Çakır-Koç, R.; Aslan, B.; Özkan, B.; Mutlu, H.; Üstün, E. Hydrogels in Regenerative Medicine. In Biomaterials in Regenerative Medicine; Dobrzanski, L.A., Ed.; IntechOpen Limited: London, UK, 2018; pp. 277-301.

5. Sinno, H.; Prakash, S. Complements and wound healing cascade: An updated review. Plast. Surg. Int. 2013, 1-7. [CrossRef] [PubMed]

6. Naseer, I.; Khan, A.; Asif, A.; Yar, M.; Haycock, J.; Rehman, I. Recent concepts in biodegradable polymers for tissue engineering paradigms: A critical review. Inter. Mater. Rev. 2018, 1-36. [CrossRef]

7. Kim, H.S.; Sun, X.; Lee, J.H.; Kim, H.W.; Fu, X.; Leong, K.W. Advanced drug delivery systems and artificial skin grafts for skin wound healing. Adv Drug Deliv Rev. 2019, 146, 1-31. [CrossRef] [PubMed]

8. Arjmandi, M.; Ramezani, M. Mechanical and tribological assessment of silica nanoparticle-alginatepolyacrylamide nanocomposite hydrogels as a cartilage replacement. J. Mech. Behav. Biomed. Mater. 2019, 95, 196-204. [CrossRef]

9. Swieszkowski, W.; Ku, D.N.; Bersee, H.E.; Kurzydlowski, K.J. An elastic material for cartilage replacement in an arthritic shoulder joint. Biomaterials 2006, 27, 1534-1541. [CrossRef]

10. Liu, M.; Zeng, X.; Ma, C.; Yi, H.; Ali, Z.; Mou, X.; Li, S.; Deng, Y.; He, N. Injectable hydrogels for cartilage and bone tissue engineering. Bone Res. 2017, 5, 1-20. [CrossRef] 
11. Chen, J.; Irianto, J.; Inamdar, S.; Pravincumar, P.; Lee, D.A.; Bader, D.L.; Knight, M.M. Cell mechanics, structure, and function are regulated by the stiffness of the three-dimensional microenvironment. Biophys. J. 2012, 103, 1188-1197. [CrossRef]

12. Summa, M.; Russo, D.; Penna, J.; Marganoli, N.; Bayer, J.S.; Bandlera, T.; Athanassion, A.; Bertorelli, R. A biocompatible sodium alginate/povidine iodine film enhances wound healing. Eur. J. Pharm Biopharm. 2018, 122, 17-24. [CrossRef]

13. Marković, D.; Zarubica, A.; Stojković, N.; Vasić, M.; Cakić, M.; Nikolić, G. Alginates and similar exopolysaccharides in biomedical application and pharmacy: Controled delivery of drugs. Adv. Technol. 2016, 5, 39-52. [CrossRef]

14. Sun, J.; Tan, H. Alginate-Based Biomaterials for Regenerative Medicine Applications. Materials 2013, 6, 1285-1309. [CrossRef] [PubMed]

15. Augst, A.D.; Kong, H.J.; Mooney, D.J. Alginate Hydrogels as Biomaterials. Macromol. Biosci. 2006, 6, 623-633. [CrossRef] [PubMed]

16. Kaczmarek-Pawelska, A. Alginate-Based Hydrogels in Regenerative Medicine. In Alginates-Recent Uses of This Natural Polymer; Pereira, L., Ed.; IntechOpen Limited: London, UK, 2019; pp. 1-12.

17. Bartkowiak-Jowsa, M.; Będziński, R.; Kozłowska, A.; Filipiak, J.; Pezowicz, C. Mechanical, rheological, fatigue, and degradation behavior of PLLA, PGLA and PDGLA as materials for vascular implants. Meccanica 2013, 48, 721-731. [CrossRef]

18. Gasperini, L.; Mano, J.F.; Reis, R.L. Natural polymers for the microencapsulation of cells. J. R. Soc. Interface 2014, 11, 1-20. [CrossRef]

19. Gibas, I.; Janik, H. Review: Synthetic polymer hydrogels for biomedical applications. Chem. Chem. Technol. 2010, 4, 297-304.

20. Barros, A.A.; Rita, A.; Duarte, C.; Pires, R.A.; Sampaio-Marques, B.; Ludovico, P.; Lima, E.; Mano, J.F.; Reis, R.L. Bioresorbable ureteral stents from natural origin polymers. J. Biomed. Mater. Res. Part B 2014, 1-10. [CrossRef]

21. Barros, A.A.; Oliveira, C.; Lima, E.; Rita, A.; Duarte, C.; Reis, R.L. Gelatin-based biodegradable ureteral stents with enhanced mechanical properties. Appl. Mater. Today 2016, 5, 9-18. [CrossRef]

22. Bartkowiak-Jowsa, M.; Będziński, R.; Chłopek, J.; Filipiak, J.; Szaraniec, B. Comparative analysis of the deformation characteristics of biodegradable polymers considered as a material for vascular stents. Polymers 2010, 56, 224-231. [CrossRef]

23. Kaczmarek-Pawelska, A.; Winiarczyk, K.; Mazurek, J. Alginate based hydrogel for tissue regeneration: Optimization, antibacterial activity and mechanical properties. J. Achiev. Mater. Manuf. Eng. 2017, 81, 35-40. [CrossRef]

24. Mørch, Ý.A.; Donati, I.; Strand, B.L.; Skijåk-Break, G. Effect of $\mathrm{Ca}^{2+}, \mathrm{Ba}^{2+}$, and $\mathrm{Sr}^{2+}$ on Alginate Microbeads. Biomacromolecules 2006, 7, 1471-1480. [CrossRef]

25. Chutipongtanate, S.; Thongboonkerd, V. Systematic comparisons of artificial urine formulas for in vitro cellular study. Anal. Biochem. 2010, 402, 110-112. [CrossRef]

26. Straccia, M.C.; Gomez d'Ayala, G.; Romano, I.; Oliva, A.; Laurienzo, P. Alginate Hydrogels Coated with Chitosan for Wound Dressing. Mar. Drugs 2015, 13, 2890-2908. [CrossRef] [PubMed]

27. Afonso, J.S.; Jorge, R.M.; Martins, P.S.; Soldi Mda, S.; Alves, O.L.; Patricio, B.; Mascarenhas, T.; Sartori, M.G.; Girao, M.J. Structural and thermal properties of polypropylene mesh used in treatment of stress urinary incontinence. Acta Bioeng. Biomech. 2009, 11, 27-33. [PubMed]

28. Chen, L.; Shen, R.; Komasa, S.; Xue, Y.; Jin, B.; Hou, Y.; Okazaki, J.; Gao, J. Drug-Loadable Calcium Alginate Hydrogel System for Use in Oral Bone Tissue Repair. Int. J. Mol. Sci. 2017, 18, 989. [CrossRef] [PubMed]

29. Yao, F.; Laudano, M.A.; Seklehner, S.; Chughtai, B.; Lee, R.K. Image-based simulation of urethral distensibility and flow resistance as a function of pelvic floor anatomy. Neurol. Urodyn. 2015, 34, 664-668. [CrossRef] [PubMed]

30. Zhang, K.; Fu, Q.; Chen, X.; Chandra, P.; Mo, X.; Song, L.; Atala, A.; Zhao, W. 3D bioprinting of urethra with PCL/PLCL blend and dual autologous cells in fibrin hydrogel: An in vitro evaluation of biomimetic mechanical property and cell growth environment. Acta Biomater. 2017, 50, 154-164. [CrossRef]

31. Feng, C.; Xu, Y.M.; Fu, Q.; Zhu, W.D.; Cui, L.; Chen, J. Evaluation of the biocompatibility and mechanical properties of naturally derived and synthetic scaffolds for urethral reconstruction. J. Biomed. Mater. Res. A 2010, 94A, 317-325. [CrossRef] 
32. Nastaj, J.; Przewlocka, A.; Rajkowska-Mysliwiec, M. Biosorption of Ni(II), Pb(II) and Zn(II) on calcium alginate beads: Equilibrium, kinetic and mechanism studies. Pol. J. Chem. Tech. 2016, 18, 81-87. [CrossRef]

33. Sadiq, A.; Choubey, A.; Bajpai, A.K. Biosorption of chromium ions by calcium alginate nanoparticles. J. Chil. Chem. Soc. 2018, 63, 4077-4081. [CrossRef]

C 2020 by the authors. Licensee MDPI, Basel, Switzerland. This article is an open access article distributed under the terms and conditions of the Creative Commons Attribution (CC BY) license (http://creativecommons.org/licenses/by/4.0/). 